\title{
Reduced proliferation in breast cancer cells contacting the neighboring adipocytes in human breast cancer tissues
}

\author{
Han Suk Ryu', Han-Byoel Lee ${ }^{2,3}$, Wonshik Hann ${ }^{2,3}$, Dong-Young Noh ${ }^{2,3}$ and Hyeong-Gon Moon ${ }^{2,3^{*}}$
}

The process of tumor formation and progression is a result of the complex interaction between malignant epithelial cells and the various cell populations in the tumor microenvironment $[1,2]$. Recently, the role of cancer-associated adipocytes in cancer progression has been an active area of research, and many studies have suggested a proinvasive and prometastatic effect of the cancer-associated adipocytes [3, 4]. The cancer-promoting effect of adipocytes seems to originate from their ability to induce inflammatory milieu and to provide an energy source for cancer cells $[5,6]$.

Human breast tissue has a unique architecture of adipose tissue surrounding the mammary glandular tissues. Many human breast cancers face the adipose tissue during their growth, and therefore there is direct contact between cancer cells and adipocytes. We have reviewed representative photographs of the 1,052 macroscopic surgical specimens of breast cancer resected between January 2006 and July 2007. This study was approved by the institutional review board (1208-046-421). In 528 patients, we were able to measure the relative ratio of tumor-adipose contact among the total circumference (Fig. 1a for a representative case and Fig. 1b for exclusion criteria), and the association between various clinico-pathological factors and the degree of tumoradipose contact was analyzed. Tumors with higher degree of direct tumor-adipose contact were more likely to be smaller tumors and low-grade tumors (Fig. 1c).

To overcome the issue of intertumoral heterogeneity, we semiquantitatively analyzed the histologic grade of cancer cells on the adipose side and on the gland side within the same tumor in 107 patients whose tumors

\footnotetext{
* Correspondence: moonhg74@snu.ac.kr

${ }^{2}$ Department of Surgery, Seoul National University College of Medicine, 28 Yongon-dong, Chongno-gu, Seoul 110-744, South Korea

${ }^{3}$ Laboratory of Breast Cancer Biology, Cancer Research Institute, Seoul National University College of Medicine, 28 Yongon-dong, Chongno-gu, Seoul 110-744, South Korea

Full list of author information is available at the end of the article
}

had moderate tumor-adipose contact (between 0.4 and 0.6 ; Fig. 1d). We measured the degree of the tubule formation, nuclear pleomorphism, and mitotic count, which are the three components of the widely used Elston-Ellis modification of the Scarff-Bloom-Richardson histologic grading system for both adipose-side and gland-side tumor cells [7]. The tumor cells on the adipose side showed significantly lower mitotic index when compared with that of the tumor cells on the gland side. The significant association with mitotic index and the cancer cells' distance to the adipose tissue was only seen in estrogen receptor-negative breast tumors (Fig. 1e, representative case shown in Fig. 1f). There was no significant difference between the adipose-side and gland-side cells in tubule formation and nuclear pleomorphism.

In conclusion, our analysis of human breast cancer samples showed that tumor cells residing close to the adipose tissue showed significantly lower mitotic count than cells distant from the adipose tissue. Our findings suggest that, contrary to the prevailing concept of the cancer-promoting role of cancer-associated adipocytes, the true interaction between cancer cells and the neighboring adipose tissue can be a complex one.

\section{Competing interests}

The authors declare that they have no competing interests.

\section{Authors' contributions}

HGM, DYN, WH and HSR conceived of the study and participated in designing the study. HSR, HGM, and HBL conducted analysis of pathology specimens. HBL, DYN, and WH collected the clinical data. All authors read and approved the final manuscript.

\section{Acknowledgements \\ This work was supported by the Basic Science Research Program through the National Research Foundation of Korea funded by the Ministry of Education, Science and Technology (2012R1A1A2005929), and by a grant from the National R\&D Program for Cancer Control, Ministry for Health and Welfare, Republic of Korea (A1220200).}

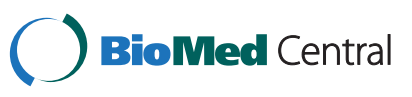

(c) 2015 Ryu et al. This is an Open Access article distributed under the terms of the Creative Commons Attribution License (http://creativecommons.org/licenses/by/4.0), which permits unrestricted use, distribution, and reproduction in any medium, provided the original work is properly credited. The Creative Commons Public Domain Dedication waiver (http:// creativecommons.org/publicdomain/zero/1.0/) applies to the data made available in this article, unless otherwise stated. 


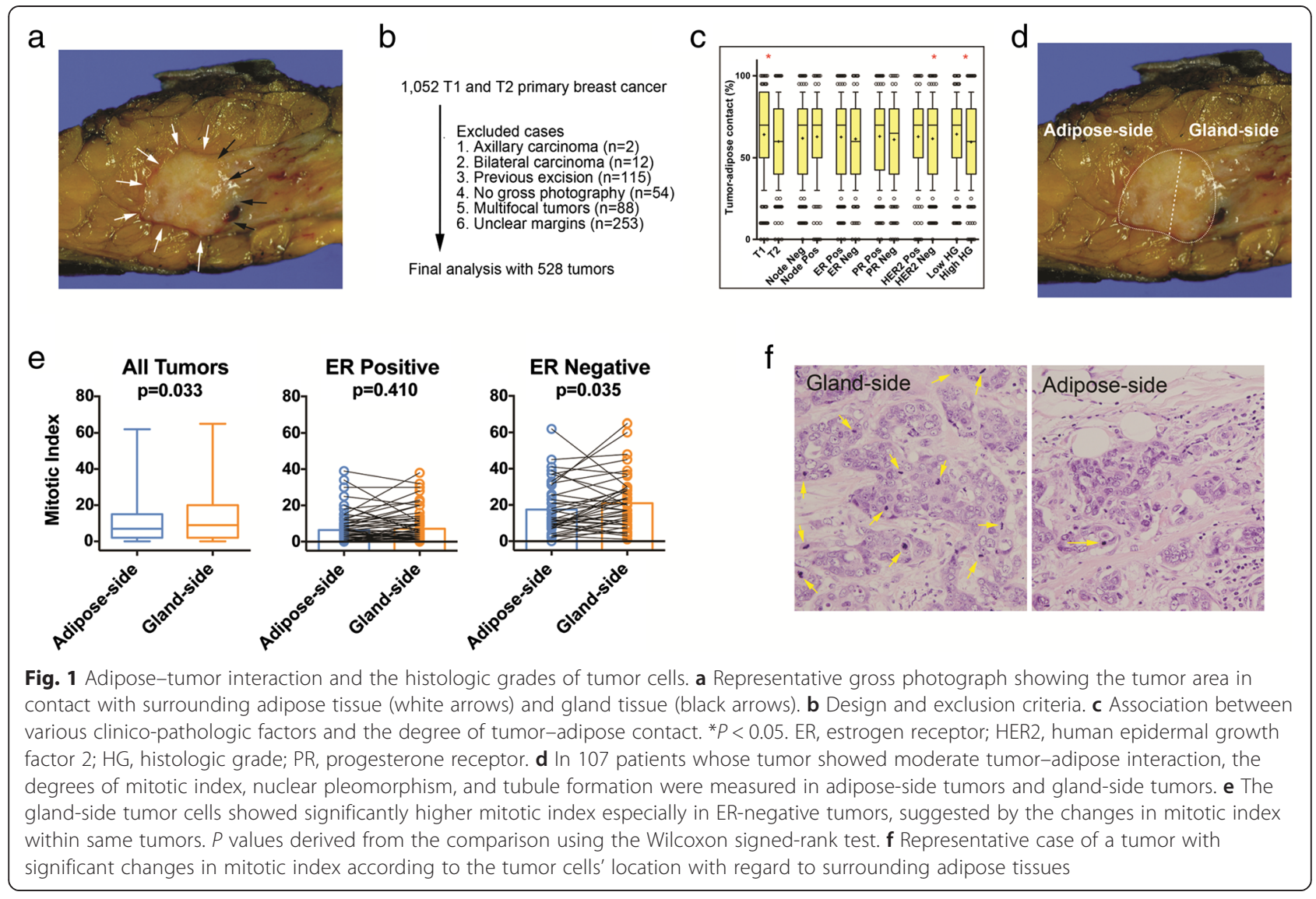

\section{Author details}

${ }^{1}$ Department of Pathology, Seoul National University College of Medicine, 28 Yongon-dong, Chongno-gu, Seoul 110-744, South Korea. ${ }^{2}$ Department of Surgery, Seoul National University College of Medicine, 28 Yongon-dong, Chongno-gu, Seoul 110-744, South Korea. ${ }^{3}$ Laboratory of Breast Cancer Biology, Cancer Research Institute, Seoul National University College of Medicine, 28 Yongon-dong, Chongno-gu, Seoul 110-744, South Korea.

Published online: 02 July 2015

\section{References}

1. Friedl P, Alexander S. Cancer invasion and the microenvironment: plasticity and reciprocity. Cell. 2011;147:992-1009.

2. McAllister SS, Weinberg RA. Tumor-host interactions: a far-reaching relationship. J Clin Oncol. 2010;28:4022-8.

3. Carter JC, Church FC. Mature breast adipocytes promote breast cancer cell motility. Exp Mol Pathol. 2012;92:312-7.

4. Bochet $L$, Lehuede C, Dauvillier S, Wang YY, Dirat B, Laurent V, et al. Adipocyte-derived fibroblasts promote tumor progression and contribute to the desmoplastic reaction in breast cancer. Cancer Res. 2013;73:5657-68.

5. Dirat B, Bochet L, Dabek M, Daviaud D, Dauvillier S, Majed B, et al. Cancerassociated adipocytes exhibit an activated phenotype and contribute to breast cancer invasion. Cancer Res. 2011;71:2455-65.

6. Nieman KM, Kenny HA, Penicka CV, Ladanyi A, Buell-Gutbrod R, Zillhardt MR, et al. Adipocytes promote ovarian cancer metastasis and provide energy for rapid tumor growth. Nat Med. 2011;17:1498-503.

7. Elston CW, Ellis IO. Pathological prognostic factors in breast cancer. I. The value of histological grade in breast cancer: experience from a large study with long-term follow-up. Histopathology. 1991;19:403-10. 